\title{
NILAI-NILAI PENDIDIKAN KARAKTER BANGSA DALAM KHAZANAH SASTRA SUNDA KLASIK: TRANSFORMASI DARI KELISANAN (ORALITY) KE KEBERAKSARAAN (LITERACY) CARITA PANTUN MUNDINGLAYA DI KUSUMAH (KAJIAN STRUKTURAL-SEMIOTIK DAN ETNOPEDAGOGI)
}

\author{
Dedi Koswara, Dingding Haerudin, Ruswendi Permana
}

email: dedi_koswara@yahoo.com

Dosen Fakultas Bahasa dan Seni UPI

\begin{abstract}
ABSTRAK
Penelitian mengenai cerita pantun Sunda dewasa ini jauh lebih sedikit jumlahnya dibandingkan dengan penelitian tentang teks sastra Sunda tertulis seperti yang berupa naskah (manuscript: handschrift). Dalam cerita pantun sarat dengan nilai-nilai pendidikan karakter, seperti dalam dalam teks Cerita pantun Mundinglaya Di Kusuma (CPMK). Beberapa alasan pentingnya dilakukan penelitian terhadap teks CPMK adalah sebagai berikut: (1) Teks CPMK belum pernah diteliti mengenai transformasi dari kelisanan ke keberaksaraannya, (2) Teks CPMK belum pernah dikaji secara struktural-semiotik, (3) Teks CPMK belum pernah dikaji berdasarkan pendekatan etnopedagogi sehingga diperoleh informasi berkenaan dengan nilai-nilai pendidikan karakter bangsa dari teks tersebut. Pendekatan sastra yang digunakan dalam penelitian ini adalah pendekatan objektif dengan metode struktural-semiotik. Hasil penelitian ini menunjukkan bahwa (1) Tradisi dan transmisi penurunan teks CPMK dilakukan secara lisan melalui pergelaran mantun, sedangkan tradisi dan transmisi teks tulis WMK tidak dapat diketahui dengan pasti karena teks itu merupakan satu teks unikum. (2) Teks lisan CPMK dan WMK memiliki struktur formal dan struktur naratif. Struktur formal CPMK terbentuk oleh 8 formula, sedangkan struktur formal WMK terbentuk oleh puisi pupuh. Struktur naratif CPMK tersusun dalam 13 fungsi dan 7 lingkungan tindakan, sedangkan struktur naratif WMK tersusun dalam 6 model aktan dan 1 model fungsional yang terdiri atas 3 tahapan jalan cerita. (3) Transformasi yang terjadi dari kelisanan (orality) CPMK ke keberaksaraan (literacy) WMK ada pada tataran bentuk formal, sedangkan tataran isi cerita tetap sama. (4) Hadirnya transformasi dari kelisanan CPMK ke keberaksaraan WMK, secara semiotik, dapat dimaknai sebagai suatu upaya untuk melestarikan dan mempertahankan eksistensi nilai ajaran moral yang tertuang dalam cerita pantun ke dalam era (zaman) wawacan sejalan dengan situasi dan kondisi serta minat masyarakat Sunda masa itu.
\end{abstract}

Kata kunci: pendidikan, karakter, etnopedagogi

\section{ABSTRACT}

The research on Sunda rhyme story today is far fewer than the study of literary texts in the form of written Sundanese script (manuscript: handschrift). In the story rhymes, it is fulled with the values of character education, as in the story text rhymes Mundinglaya In Kusuma (CPMK). Some important reasons to do research on CPMK text are as follows: (1) CPMK text has not been investigated regarding the transformation from orally until its script, (2) CPMK text has never been studied in a structural-semiotic, (3) CPMK text has never been assessed, based on approach of ethnopedagogy so that it is obtained the information regarding to the values of the national character from the text. Literary approach that is used in this study is objective approach by structural-semiotic method. The results of this study indicate that (1) Tradition and decrease transmission of CPMK text was done orally through rhyming performances, while tradition and written text of WMK transmission could not be known exactly because the text is an unic text. (2) The oral text of CPMK and WMK has a formal structure and narrative structure. CPMK formal structure is formed by 8 formulas, while the formal structure of WMK itself is formed by the poem Canto. CPMK narrative structure arranged in 13 functions and 7 environmental actions, meanwhile the narrative structure of WMK are arranged in 6 models and 1 functional model that consist of three stages of the storyline. (3) The transformation occurred from orally CPMK to literacy WMK was existed at the level of a formal form, whereas the level of the story content was remains the same. (4) The presence of the transformation from orally of CPMK to the literacy of WMK in semiotic can be interpreted as an effort to preserve and maintain the existence of the value of the moral teachings contained in the story rhyme into that era wawacan in line with the circumstances and future interest of Sunda people at that time.

Keywords: education, character, ethnopedagogy 


\section{PENDAHULUAN}

Di dalam khazanah sastra Sunda dikenal carita pantun. Cerita pantun merupakan salah satu genre sastra lisan Sunda yang keberadaannya sudah hampir punah. Cerita pantun adalah cerita yang dituturkan oleh seorang jurupantun (pemantun) dalam pergelaran seni tutur yang disebut mantun. Pergelaran cerita pantun ini biasanya berlangsung semalam suntuk dimulai setelah Isya sampai menjelang Subuh. Penuturannya dilakukan dengan cara dihapal secara lisan (Rosidi, 2000:493; Iskandarwassid, 1996: 102).

Cerita pantun merupakan salah satu hasil sastra lisan Sunda asli yang sudah ada pada tahun 1518 Masehi (Atja \& Danasasmita, 1981: 40). Keterangan mengenai cerita pantun, lelakon pantun atau seni mantun ada dalam naskah Sunda kuna Sanghyang Siksa Kanda Ng Karesian (1440 Saka; 1518 Masehi). Dalam naskah tersebut, di antaranya, disebutkan empat lakon cerita pantun, yaitu Langgalarang, Banyakcatra, Siliwangi, dan Haturwangi.

Pada umumnya lelakon pantun itu mengisahkan cerita masa lalu (baheula) tentang raja-raja atau putra-putri raja keturunan Pajajaran. Bertolak dari isi ceritanya yang banyak mengisahkan kebesaran dan keagungan raja Pajajaran, Prabu Siliwangi, diduga bahwa cerita pantun itu lahir pada zaman Pajajaran. Akan tetapi ada penjelasaan lain yang menyatakan bahwa ada pula cerita pantun yang mengisahkan kebesaran dan keagungan kerajaan yang lebih tua, yaitu Kerajaan Pasir Batang Anu Girang dalam cerita pantun Lutung Kasarung dan Kerajaan Galuh dalam Carita Pantun Ciung Wanara yang telah berdiri jauh lebih dahulu daripada Kerajaan Pajajaran.

Dilihat dari segi bentuknya, cerita pantun berbentuk puisi naratif. Sebagai puisi, kekuatan pantun terutama dalam menentukan pilihan kata yang tepat untuk menggambarkan perbandingan-perbandingan karakteristik tokoh yang sangat plastis. Sebagai contoh, Rosidi (1966: 2) mengungkapkan bahwa untuk melukiskan tubuh tokoh raksasa Yaksa Mayuta yang amat tinggi besar, dalam cerita pantun Mundinglaya di Kusumah, diperikan lukisan huluna butak sabeulah/balas pasundul jeung langit (kepalanya botak sebelah karena sering bersentuhan dengan langit). Sebagai bentuk puisi naratif, cerita pantun memiliki struktur cerita yang relatif tetap, yaitu sebagai berikut: Rajah Bubuka Mangkat Carita (Mulai berkisah) — Lukisanlukisan: lukisan keagungan kerajaan, lukisan kecantikan putri dan ketampanan putra raja, lukisan putri dan putra raja berdandan, lukisan putri berjalan, lukisan putri menenun, lukisan hutan lebat, lukisan peperangan, lukisan pesta perkawinan dan pesta negara — Rajah Panutup (Rosidi, 1966: 3).

Lakon CPMK adalah cermin jiwa dan masyarakat Sunda zamannya. Sebagaimana diungkapkan Rosidi (1966:43) bahwa lakon pantun yang merupakan manifestasi jiwa Sunda buhun memperlihatkan jiwa dan kepercayaan masyarakat yang menghasilkannya. Dalam lakon pantun digambarkan filsafat dan kepercayaan leluhur orang Sunda dahulu yang hidup di alam agraris. Kisah perjalanan spiritual pahlawan budaya dalam CPMK, pada hakikatnya adalah perjalanan dua tokoh utama yang manunggal, yaitu pahlawan budaya di satu sisi, dan Tuhan (dewa, tokoh titisan dewa) di pihak lain.

Penelitian mengenai cerita pantun Sunda dewasa ini jauh lebih sedikit jumlahnya dibandingkan dengan penelitian tentang teks sastra Sunda tertulis seperti yang berupa naskah (manuscript: handschrift). Hal itu terjadi, di antaranya, karena sastra lisan Sunda ini kini sudah mulai lenyap oleh perkembangan zaman. Oleh karena itu, para penutur cerita pantun Sunda (jurupantun) yang dahulu pernah populer melakukan pergelaran dalam acara-acara tertentu serta 
menjadi idola di masyarakat, kini ruang lingkup aktivitas mereka semakin sempit dan berkurang.

Dari beberapa penelitian terdahulu yang berkaitan dengan CPMK belum pernah dilakukan pengkajian dari segi bentuk dan isinya. Demikian juga belum pernah dilakukan penelitian tentang transformasi dari kelisanan (orality) CPMK ke keberaksaraan (literacy)WMK; juga belum pernah dianalisis struktur naratifnya, baik secara struktural maupun secara semiotik; apalagi dilakukan pengkajian berdasarkan nilai-nilai pendidikan karakter bangsa (etnopedagogi) terhadap kandungan teks CPMK. Padahal teks CPMK ini termasuk salah satu carita pantun tertua, di samping Carita Pantun Ciung Wanara dan Carita Pantun Lutung Kasarung, yang masih dianggap sakral dan ritual oleh Ki Juru Pantun.

Tanpa pendokumentasian dan penelitian terhadap cerita pantun Sunda, seperti Carita Pantun Mundinglaya di Kusumah (CPMK) secara dini, mustahil isi teks sastra lisan Sunda ini dapat diketahui dan kemudian dapat diwariskan kepada generasi sekarang dan generasi mendatang. Hal itu seperti terbukti dari apa yang telah dilakukan oleh beberapa orang peminat sastra Sunda dan peminat kebudayaan Sunda umumnya. Pada abad ke-19 dilakukan oleh orang Barat dan pada abad ke-20 dilakukan oleh orang Sunda sendiri.

\section{METODE PENELITIAN}

Metode penelitian yang dipakai dalam penelitian ini adalah metode deskriptifkualitatif. Pendekatan sastra yang digunakan dalam penelitian ini adalah pendekatan objektif dengan metode struktural-semiotik. Metode struktural dimaksudkan untuk memahami unsur-unsur cerita (struktur cerita) CPMK yang meliputi: tema, alur, tokoh dan penokohan, latar cerita, serta hubungan fungsi antarunsurnya. Selanjutnya, untuk memahami makna CPMK secara menyeluruh diterapkan metode semiotik. Di saping itu, diterapkan pula pendekatan sastra lainnya, yaitu pendekatan mimetik, ekspresif, dan pragmatik. Pendekatan mimetik digunakan untuk memahami teks dalam tautannya dengan alam semesta (dalam hal ini kosmologi-religio-magis masyarakat Sunda yang terlukis dalam CPMK); pendekatan ekspresif digunakan untuk mengetahui fungsi dan makna teks CPMK menurut penutur teks; sedangkan pendekatan pragmatik digunakan untuk memahami pengaruh teks CPMK terhadap masyarakat pembaca.

Teknik pengumpulan data yang dilakukan di dalam penelitian ini adalah studi pustaka dan teknik analisis. Teknik studi pustaka dilakukan di berbagai perpustakaan di Jawa Barat untuk mendapatkan teks CPMK dan teks WMK. Di samping itu, studi pustaka juga dilakukan untuk memperoleh informasi hasil tulisan lain yang berkenaan dengan penelitian atau pembahasan CPMK atau WMK. Teknik analisis dilakukan dalam menganalisis teks CPMK dan WMK berdasarkan kajian teori kelisanan dan keberaksaraan dari segi struktur formal dan struktur naratifnya; dari segi transformasi kelisanan CPMK ke keberaksaraan WMK; dari segi semiotiknya; dan dari segi pendidikan karakternya.

Data penelitian ini adalah teks Carita Pantun Mundinglaya Di Kusumah (CPMK) hasil transkripsi Proyek Penelitian Pantun dan Folklor Sunda (Rosidi, 1970) dan Wawacan Mundinglaya Di Kusumah (WMK) (M.A. Salmun, 1974). Kedua data tersebut dijadikan data primer dalam penelitian ini, sedangkan data skundernya dalam bentuk karangan lain yang telah ditransformasi ke dalam bentuk cerita novel dan Gending Karesmen serta hasil bahasan yang berkaitan dengan CPMK.

Data primer CPMK dan WMK yang yang dianalisis dalam penelitian ini adalah dalam bentuk naskah yang diperoleh dari perpustakaan di Jawa Barat, sedangkan data 
skundernya dalam bentuk bentuk naskah Gending Karesmen dan Roman atau Novel.

\section{HASIL DAN PEMBAHASAN}

Hasil yang dicapai dalam penelitian ini berkenaan dengan: struktur naratif kelisanan (orality) Carita Pantun Mundinglaya Di Kusumah (CPMK) dan struktur naratif keberaksaraan (literacy) Wawacan Mundinglaya Di Kusumah (WMK), transformasi dari kelisanan CPMK ke keberaksaraan WMK, pemaknaan semiotik CPMK, dan nilai-nilai pendidikan karakter bangsa di dalam CPMK.

1) Struktur Naratif Carita Pantun Mundinglaya Di Kusumah (CPMK)

Pada bagian ini dibahas yang berkenaan dengan ringkasan Carita Pantun Mundinglaya Di Kusumah (CPMK) berikut dan strukturnya. Adapun ringkasan $C P M K$ sebagai beriktu ini.

\section{“CARITA PANTUN MUNDINGLAYA DI KUSUMAH"}

Prabu Siliwangi menjadi raja di Pajajaran. Ia memiliki dua orang patih bernama Kidang Pananjung dan Gelap Nyawang yang berperawakan tinggi besar dan sakti.

Pada suatu waktu, Prabu Siliwangi pergi bertapa ke Gunung Hambalang karena ingin mendapat putra dan istri untuk dijadikan prameswari, yaitu Nyi Padmawati, putri Pohaci Wirumananggay dari Kahyangan.

Pada waktu Padmawati mengandung, ia menginginkan honje. Lalu raja menyuruh Lengser mencarinya ke Negara Kuta Pandek di Muara Beres. Dari Geger Malela, putra Rangga Malela di Muara Beres didapatkannya honje delapan pasak yang ditukarnya dengan uang delapan keton. Ketika itu, di Muara Beres Nyi Gambir Wangi pun tengah mengidam, sama menginginkan honje, tetapi honje sudah dijual kepada utusan Ratu Pajajaran.

Lengser Muara Beres disuruh untuk mengembalikan uang empat keton, yang akan ditukar dengan honje empat pasak. Lengser Pajajaran menolaknya. Akhirnya kedua Lengser tersebut berperang memperebutkan honje. Tak ada yang kalah, kemudian mereka dilerai oleh Gajah Siluman. Honje akhirnya dibagi dua dengan perjanjian bahwa kedua bayi itu setelah dewasa harus dikawinkan.

Nyi Gambir Wangi menginginkan terung pait yang ingin dimakannya berbagi dengan Padmawati. Terung itu dibelah oleh Patih Gelap Nyawang, sesudah itu Raja bersabda kepada seluruh rakyat bahwa bayi yang masih dalam kandungan itu sudah dijodohkan.

Nyi Padmawati dari Gunung Gumuruh melahirkan seorang putra laki-laki yang diberi nama Mundinglaya Di Kusumah, sedangkan Nyi Gambir Wangi melahirkan seorang perempuan yang diberi nama Dewi Asri.

Prabu Guru Gantangan dari Negeri Kuta Barang sebagai ua Mundinglaya mengangkatnya sebagai putra, dengan alasan untuk dididik kesaktian. Mundinglaya menjadi sakti dan membuat takut Guru Gantangan bahwa kekuasaannya akan direbut oleh Mundinglaya. Oleh sebab itu, Mundinglaya dimasukkan ke dalam penjara besi kemudian ditenggelamkan ke dalam Leuwi Sipatahunan.

Paman Mundinglaya, yaitu Jaksa Seda Kawasa, Aria Patih Sagara, Gelap Nyawang dan Kidang Pananjung berpirasat jelek terhadap Mundinglaya. Kemudian menyusulnya ke Kuta Barang dan memarahi Prabu Guru Gantangan. Akan tetapi, Mundinglaya dibiarkannya sebagai suatu ujian keprihatinan. Hal itu tidak dikabarkan kepada ibu dan ayahandanya di Pajajaran.

Pohaci Wiru Mananggay mengirimkan impian kepada Padmawati bahwa dia harus mendapat lalayang kencana milik Guriang Tujuh di Sorong Kencana. Padmawati menyampaikan mimpi itu kepada raja. Waktu disayembarakan kepada putra dan 
para ponggawa tidak ada yang sanggup mencarinya. Oleh karena itu, Padmawati yang memimpikannya harus membuktikannya sendiri. Kalau tidak akan dipenggal kepalanya.

Nyi Padmawati teringat kepada putranya Mundinglaya, lalu menyuruh Gelap Nyawang dan Kidang Pananjung untuk menjemputnya di Kuta Barang. Mundinglaya diambil dari Leuwi Sipatahunan lalu dibawa ke Pajajaran.

Mundinglaya menyanggupi untuk mendapatkan Layang Kencana. Kemudian ia berangkat diantar oleh Patih Jaksa Seda Kawasa, Gelap Nyawang, Kidang Pananjung, Patih Ratna Jaya, dan Liman Sanjaya, dari Gunung Gumuruh beserta Lengsernya. Dengan perahu kencana ciptaan Kidang Pananjung mereka berlayar melalui Leuwi Sipatahunan dan Bengawan Cihaliwung. Sampailah di Muara Beres, lalu Mundinglaya menemui tunangannya Dewi Asri. Kemudian Mundinglaya meneruskan perjalannya. Di Sanghyang Cadas Patenggang semua pengantarnya ditinggalkan di dalam perahu.

Di dalam perjalanan, di sebuah hutan belantara, Mundinglaya bertemu dengan Yaksa Mayuta. Dia dikunyah, lalu ditelan raksasa itu. Setelah mengambil azimat raksasa di langit-langit mulutnya, yang kemudian ditelannya, Mundinglaya bertambah sakti. Kemudian Yaksa Mayuta dapat dikalahkannya.

Mundinglaya meneruskan perjalan-annya ke langit, menemui neneknya di Kahiyangan untuk meminta Lalayang Kencana yang diimpikan ibunya. Oleh neneknya, Wiru Manunggay, Mundinglaya diperintahkan menjadi angin supaya dapat menerbangkan Lalayang Kencana. Angin puting beliung menerbangkan Lalayang Kencana, lalu disusul oleh Guriang Tujuh. Guriang Tujuh perang dengan Mundinglaya sampai meninggal oleh keris mereka.

Sukma Mundinglaya keluar dari jasadnya, lalu mengisap sambil mementerakan supaya hidup kembali.

Prabu Guru Gantangan di Negara Kuta Barang, mempunyai putra-putra angkat, seperti Sunten Jaya, Demang Rangga Kasonten, Aria Disonten dan Dewi Aria Kancana. Sunten Jaya diperintahkan ayah angkatnya melamar Dewi Asri karena mendengar bahwa Mundinglaya sudah meninggal oleh Guriang Tujuh. Sunten Jaya yang angkuh dan buruk perangainya bersaudara angkatnya pergi ke Muara Beres meminang Dewi Asri kepada kakaknya, raden Geger Malela. Dewi Asri menolak lamaran Sunten Jaya karena sudah dipertunangkan dengan Mundinglaya. Akan tetapi karena dipaksa, ia menerima pinangan itu dengan sarat bahwa Sunten Jaya harus memenuhi permintanyaannya, yaitu sebuah negara dengan segala isinya. Sunten Jaya marah karena tidak mungkin permintaan itu dapat dipenuhinya. Namun permintaan itu disanggupi oleh Prabu Guru Gantangan. Dewi Asri yang dipaksa menikah dengan Sunten Jaya membuat bermacam ulah dengan tujuan agar pernikahan batal.

Mundinglaya yang sudah hidup kembali dan sedang bertapa mendapat pirasat buruk, ia bermimpi kepalanya diserang topan, tiangnya patah, kapal pun pecah dan karam di laut. Dia ingat kepada tunangannya. Waktu dilihatnya tabir mimpi tersebut, tampak olehnya bahwa Dewi asri sedang dinikahkan dengan Sunten Jaya. Mundinglaya berpamit kepada neneknya. Sudah dihadiahi buli-buli berisi air cikahuripan dan keris pusaka, Mundinglaya turun dari Jabaning Langit membawa Lalayang Kencana disertai Munding Sangkala Wisesa jelmaan Guriang Tujuh.

Setibanya di Sanghyang cadas Patenggang dijemputnya pamannya yang ada di dalam perahu. Selanjutnya Kidang Pananjung memantrai Sangkala Wisesa sehingga tidur lelap. Dewi Asri mendapat firasat, lalu dia menciptakan bantal guling menjadi dirinya 
kemudian ia mandi di sungai dan bertemulah dengan Mundinglaya. Dewi Asri pergi bersama Mundinglaya berlayar naik perahu kencana.

Munding Sangkala Wisesa dibangunkan dari tidurnya, kemudian disuruh pergi ke Muara Beres untuk mengamuk seluruh prajurit, Patih Halang Barang dan Prabu Guru Gantangan. Kepada Raden Geger Malaka, Sangkala Wisesa mengatakan bahwa ia sedang mencari saudaranya Mundinglaya. Oleh Geger Malela diterima lalu dibawa ke dalam keraton.

Mundinglaya dan Dewi Asri pergi bersamasamake MuaraBeresmengadakanperarakan. Setibanya di keraton, kemudian mereka naik ke papanggungan kancana dan bersantap bersama. Sunten Jaya akhirnya mengetahui bahwa ia ditipu lalu ia naik ke papanggungan untuk memerangi Mundinglaya. Namun terkena mantra Mundinglaya, ia menjadi tak berdaya. Dewi Asri dan Mundinglaya lalu menikah.

Sementara itu, Jaksa Pajajaran, Demang Patih Rangga Gading, Paman Murugul Matri Agung dan Purwakalih datang ke Muara Beres menilah yang menikah dan akan melerai pertengkaran. Sunten Jaya datang meminta kembali meminta harta bendanya yang sejumlah 25 kapal. Rangga Gading bertanya, siap yang mula-mula melamar Dewi Asri? Rakyat Kuta Barang semua memihak kepada Sunten Jaya karena Sunten Jayalah yang lebih dahulu melamar. Tetapi Patih Gajah Siluman dari Karang Siluman menyuruh Lengser Pajajaran menceritakan asal mula hubungan kedua putra-putri itu. Akhirnya mereka mengetahui bahwa Mundinglaya dan Dewi Asri sudah dijodohkan sedang dikandung. Sunten Jaya harus mengalah tetapi dia marah dan menantang perang kepada Mundinglaya. Namun Sunten Jaya dan pasukannya dikalahkan oleh Munding Sangkala Wisesa.

Mundinglaya berbahagia menjadi pengantin baru yang kaya raya. Dia diangkat menjadi raja muda yang berpermaisurikan Dewi Asri dan Anten Kancana, adik Sunten Jaya.

(Dari Cerita Pantun Mundinglaya Di Kusumah tuturan Ki Atjeng Tamadipura, Situraja, Sumedang, 1970).

Wacana di atas adalah sebuah ringkasan cerita pantun yang dianggap sakral dan ritual oleh masyarakat Sunda. Di samping cerita pantun Mundinglaya, ada lagi cerita pantun lain yang dianggap sakral, yaitu Cerita Pantun Ciung Wanara dan Cerita Pantun Lutung Kasarung.

Cerita pantun atau lakon pantun yaitu cerita yang biasa dilakonkan oleh tukang pantun (juru pantun) dalam pergelaran ruatan (ritual) yang disebut mantun. Biasanya pergelaran pantun itu berlangsung semalam suntuk dimulai setelah Isya sampai Subuh (Iskandarwassid, 1996: 100).

Dalam pementasannya ada bagian yang diceritakan dan ada pula bagian yang ditembangkan dengan diiringi petikan kecapi. Cerita yang dipantunkan itu seluruhnya dihapal di luar kepala oleh Ki Jurupantun. Oleh karena itu, cerita pantun termasuk cerita rakyat asli milik orang Sunda. Cerita pantun disebarkan secara lisan. Itulah sebabnya terjadi banyak versi dalam cerita pantun.

Ceritapantunlahirpadaabadke-14. Alasannya karena dalam cerita pantun umumnya disinggung mengenai keadaan Kerajaan Pajajaran. Ada pula yang menganggap bahwa cerita pantun itu lahir jauh sebelum Kerajaan Pajajaran itu berdiri. Alasannya karena di dalam sebuah cerita pantun yang berjudul Cerita Pantun Ciung Wanara diceritakan keadaan Kerajaan Galuh. Demiukian juga, dalam Cerita Pantun Lutung Kasarung diceritakan tentang Kerajaan Pasir Batang. Baik Kerajaanm Galuh maupun Kerajaan Pasir Batang, berdirinya jauh sebelum Kerajaan Pajajaran. Dalam hubungan ini, Rusyana (1987: 80) menyebutkan bahwa tempat dan waktu yang diceritakan dalam 
cerita pantun pada umumnya jaman Kerajaan Galuh (yang berdiri pada abad ke-8 dan berakhir pada abad ke-13), dan Kerajaan Pajajaran (setelah Galuh sampai tahun 1579). Keterangan yang paling kuat dan kuna mengenai lahirnya cerita pantun, lelakon pantun, atau seni mantun, ada dalam naskah Sanghyang Siksa Kanda ng Karesian (1440 Saks; 1518 masehi). Dalam naskah tersebut dikatakan ada empat lelakon pantun, yaitu Langgalarang, Banyakcatra, Siliwangi, Haturwangi (Iskandarwassid, 1996: 100).

\section{2) Struktur Carita Pantun}

Melihat susunan ceritanya di dalam cerita pantun itu ada bagian yang disebut rajah, ada bagian yang diceritakan, ada bagian yang didialogkan dan ada bagian yang ditembangkan. Rangkai/susunanceritapantun itu pada umumnya sudah tetap, dimulai rajah pamuka, mangkat carita, mendeskripsikan keadaan kerajaan dan tokoh cerita dan yang berpetualang, kemudian diakhiri oleh rajah pamunah atau rajah penutup (Rosidi, 1983). Berdasarkan alurnya, cerita pantun terdiri atas unsur-unsur (secara berturut-turut) yaitu perpisahan (keberangkatan) - ujian (inisiasi) - kembali. Alur cerita demikian disebut nuclear unit, yaitu alur yang dalam kenyataannya dapat berkembang menjadi beberapa variasi, yaitu sebagai berikut. 1) Perpisahan (mungkin ada atau tidak), meliputi (a) datangnya panggilan untuk bertualang, (b) menolak untuk bertualang, (c) bantuan gaib yang datang kepada yang bertualang; 2) Ujian (Inisiasi), meliputi (a) perjalanan cobaan yang berbahaya, (b) pertemuan dengan dewa penyelamat, (c) ada wanita penggoda, (d) apoteosis, pahlawan menjadi bersifat dewata, (e) anugerah utama; 3) kembali, meliputi (a) menolak kembali, (b) melarikan diri secara gaib, (c) bantuan/ pertolongan dari pihak luar, (d) jadi penguasa dunia jasmani dan rohani, (e) hidup bahagia (bebas, leluasa) sebagai pernyataan adanya hikmah anugerah.
3) Nilai-nilai Pendidikan Karakter Bangsa (Etnopedagogi) di dalam CPMK

Nilai-nilai pendidikan karakter bangsa (etnopedagogi) telah menjadi sebuah pemeo di dalam masyarakat kita. Istilah ini dikenalnya dari referensi asing yang tidak mengakar pada kultur atau pada kearifan budaya lokal warisan karuhun (nenek moyang) yang telah membesarkannya (Megawangi, 2004).

Dari kedua tema dalam CPMK tersebut dapat dikembangkan menjadi sebuah amanat yang lebih sepesifik, yaitu (1) manusia hendaknya bersabar dan bertawakal dalam menghadapi segala cobaan dan penderitaan hidup, (2) manusia hendaknya selalu mengindahkan nasihat orang tua agar hidup selamat dan sejahtera dunia dan akherat, (3) seorang anak hendaknya senantiasa berbakti, taat dan patuh kepada orang tua.

4) Refleksi Nilai-nilai Pendidikan Karakter Bangsa yang Terungkap dari Tindakan Tokoh Cerita di dalam CPMK

Dalam setiap perjalanan yang dilalui tokoh Mundinglaya selalu ada ujian dan cobaan yang merintangi pencapaian cita-citanya. Ia selalu dihadapkan pada dua kasus yang oposan binner (berlawanan).

Dari rentetan kasus itu dapat kita ungkapnilainilai pendidikan karakter bangsa bahwa seseorang yang tengah berjuang menegakkan kebenaran dan keadilan harus memiliki keteguhan hati, memiliki kekuatan lahir dan batin, untuk melawan para penentang dari kelompok orang-orang dzalim. Ketika yang hak itu ditegakkan, maka saat itu pula kebatilan datang menyerang. Namun tidak usah khawatir karena pada akhirnya dengan berbekal keyakinan dan keteguhan hati bahwa Sang Khalik akan berpihak dan memenangkan yang hak dan mengalahkan kebatilan itu. Inilah sebenarnya esensi atau makna dibalik CPMK yang menjadi dasar atau tema cerita sesungguhnya yang ingin disampaikan kepada para pembaca atau para penonton sejak ratusan tahun silam. 
Hal ini secara tidak langsung dimaksudkan agar menjadi pembelajaran dan pendidikan karakter bagi bangsa Sunda dalam menata, mengelola tatanan hidup bermasyarakat dan bernegara.

Kisah CPMK ini berakhir dengan sebuah pahala bagi seorang pahlawan pembela kebenaran dan hukuman bagi seorang yang berbuat jahat. Pada akhir cerita Mundinglaya menikah dengan Dewi Asri dan diangkat menjadi Raja Pajajaran, menggantikan Prabu Siliwangi, sedangkan Guru Gantangan dan Sunten Jaya mendapat hukuman atas tindak kejahatannya.

Dari rentetan peristiwa yang dalami oleh tokoh-tokoh cerita dalam CPMK terekam tujuan hidup manusia Sunda pada zamannya. Tokoh Mundinglaya adalah ikon manusia Sunda yang memiliki tujuan hidup: hurip, waras, cageur, bageur, bener, pinter, ludeung, silih asah, silih asih, silih asuh, jeung sineger tengah.

Mundinglaya Di Kusumah (MDK) adalah tokoh ideal manusia sempurna yang menjadi dambaan orang Sunda pada umumnya. Dia adalah manusia yang paripurna lahir dan batin. Tujuan hidup seperti yang dicapai tokoh MDK perlu dipedomani oleh manusia Sunda masa kini dan masa mendatang. Keadaan kejiwaan yang waras, cageur, bageur, bener, pinter, ludeung, silih asah, silih asih, silih asuh menjadi dasar pencapaian tujuan hidup hurip (hidup sejahtera lahir dan batin) sekaligus memproporsionalkan eksistensi diri untuk menjadi manusia yang disebut sineger tengah (seimbang dan wajar) dalam strata sosial (habluminanas) yang horizontal dan strata religius (habluminallah) yang vertikal.

\section{KESIMPULAN}

Ada empat buah kesimpulan yang dapat dikemukakan sebagai hasil temuan di dalam penelitian ini, yaitu sebagai berikut: (1) Berdasarkan penerapan teori Propp
(1987) diketahui bahwa sastra lisan CPMK memiliki 13 fungsi cerita dan 7 lingkungan tindakan. Ketiga belas fungsi tersebut adalah: keberangkatan, kejahatan, penyelamatan, perjuangan, kemenangan, penerimaan unsur magis, fungsi pertama donor, kepulangan, tuntutan yang tidak mendasar, tugas yang sulit, penyelesaian tugas, penyingkapan tabir, dan perkawinan (naik tahta). Ketiga belas fungsi naratif CPSK di atas dapat dikelompokkan ke dalam 7 lingkungan tindakan, yaitu (1) Lingkungan tindakan kejahatan, (2) Lingkungan tindakan donor (pembekal), (3) Lingkungan tindakan pembantu, (4) Lingkungan tindakan seorang putri dan ayahandanya, (5) Lingkungan tindakan perantara, (6) Lingkungan tindakan pahlawan, (7) Lingkungan tindakan pahlawan palsu; (2) Secara semiotik, teks CPMK dan WMK merupakan tanda yang perlu dimaknai. Berdasarkan penerapan teori semiotik Propp (1987), diketahui bahwa CPMK dan WMK memiliki tanda dalam hubungan trio, yaitu dengan groundnya, dengan acuannya, dan dengan interpretannya. Tanda-tanda tersebut berupa ikon, indeks, dan simbol. Tandatanda tersebut di dalam CPMK mengacu pada sebuah referent yang dapat dimaknai sebagai adanya keyakinan masyarakat Sunda masa lalu terhadap kosmologi Sunda lama. Hal itu dapat ditemukan di antaranya dari rajah bubuka 'rajah pembuka' yang terdapat pada awal cerita CPMK; (3) Dalam CPMK diperoleh nilai-nilai pendidikan karakter bangsa (Etnopedagogi) yang mengakar pada kultur atau pada kearifan budaya lokal warisan karuhun (nenek moyang), yaitu bahwa: (1) manusia hendaknya bersabar dan bertawakal dalam menghadapi segala cobaan dan penderitaan hidup, (2) manusia hendaknya selalu mengindahkan nasihat orang tua agar hidup selamat dan sejahtera dunia dan akherat, (3) seorang anak hendaknya senantiasa berbakti, taat dan patuh kepada orang tua; (4) Refleksi nilainilai pendidikan karakter bangsa terungkap dari tindakan tokoh CPMK tergambar 
dalam rentetan peristiwa yang dalami oleh tokoh cerita yang memiliki tujuan hidup, yaitu: hurip, waras, cageur, bageur, bener, pinter, ludeung, silih asah, silih asih, silih asuh, jeung sineger tengah, dengan harapan mencapai hirup jeung hurip (hidup sejahtera lahir dan batin) sebagai manusia yang sineger tengah (seimbang dan wajar) dalam strata sosial (habluminanas) yang horizontal dan strata religius (habluminallah) yang vertikal.

\section{DAFTAR PUSTAKA}

Atja dan Saleh Danasasmita. 1972. Sanghyang Siksa Kanda Ng Karesian (Naskah Sunda Kuno Tahun 1518 Masehi). Jawa Barat: Proyek Pengembangan Permuseuman.

Iskandarwassid. 1996. Kamus Istilah Sastra. Bandung: Geger Sunten

Megawangi, Ratna. 2004. Pendidikan Karakter: Solusi yang tepat untuk membangun bangsa. Jakarta: Star Energy (Kakap) Ltd.

Propp, Vladimir. 1987. Morfologi Cerita Rakyat. Terjemahan Noriah Taslim. Malaysia: Percetakan Sais Baru Sdn. Bhd.

Rosidi, Ajip (Ed.) 1970. Carita Pantun Mundinglaya di Kusumah. Jakarta: Pusat Pembinaan dan Pengembangan Bahasa.

Rosidi, Ajip (Pimpinan Redaksi). 2000. Ensiklopedi Sunda., Alam, Manusia dan Budaya. Jakarta: Pustaka Jaya.

Rosidi, Ajip. 1966. Kesusastran Sunda Dewasa Ini. Majalengka: Tjupumanik.

Rosidi, Ajip. 1983. Ngalanglang Kasusastraan Sunda. Bandung: Pustaka Jaya

Rusyana, Yus. 1987. Panyungsi Sastra. Bandung: Gunung Larang

Salmun, M.A. 1974. Wawacan Mundinglaya di Kusumah. Jakarta: Pusat Pembinaan dan Pengembangan Bahasa 